\title{
International Research Journal of Optics and Photonics
} (DOI:10.28933/IRJOP)

\section{Infrared Thermography as a Predictor of Inflammatory Response in the Elderly with Arthritis}

\author{
Miarka, B.1, Quintana, M.S3, Moreira, D.G2,3, Brito, C.J1, 3
}

1Universidade Federal de Juiz de Fora - Campus Governador Valadares 2Instituto Federal Minas Gerais - Campus Governador Valadares 3Universidad Politécnica de Madrid

\begin{abstract}
Among the physiological responses associated with osteoarthritis, the increase in muscle and epithelial temperature is an indicator of pro-inflammatory status. However, however, the association between epithelial temperature increase and osteoarthritis in elderly individuals was not yet measured. Therefore, the objective of the study was to investigate whether the thermographic pattern is able to predict the inflammatory in lower limbs in individuals with osteoarthritis. The sample consisted of 10 participants with arthritis separated by men (MW: 2; age: 75 \pm 10.2 years; body mass: $78.5 \pm 12.2 \mathrm{~kg}$; height: $164.5 \pm 8.6 \mathrm{~cm}$ ) and women (FW: 8, age: $75 \pm 10.2$ years, body mass: $69.1 \pm$ $9.5 \mathrm{~kg}$, height: $153.6 \pm 9.9 \mathrm{~cm}$ ). Infrared thermography (FLIR® thermography) was performed in 6 regions of interest (IR) in the coronal (anterior and posterior) and sagittal (left and right portions) planes. To obtain predictive models, regression analyzes were performed for both sexes, $p \leq 0.05$. The results indicated that the presence of inflammation could be predicted by the following models for men: RI Posterior thigh $(\operatorname{Exp}(B)=3.02395 \%$ C.I. $=1.065$ to 8.578, S.E $=0.532$, Wald $=4.331, p=0.038$ ). While women showed two predictive IRs in the first model, calf thermography $(\operatorname{Exp}(B)=3.844295 \% \mathrm{Cl}=0.167$ to $1.00, \mathrm{SE}=$ 0.457 , Wald $=3.84, p=0.050$ ) and, in the second model, the left anterior calf $(\operatorname{Exp}(B)=6.21195 \% \mathrm{Cl}=1.447$ to 21.976 , SE $=$ 0.694 , Wald $=5.639, p=0.013)$ and left anterior cinnamon $(E x p$ $(B)=7.36895 \% \mathrm{Cl}=0.024$ to $0.547, \mathrm{SE}=0.800$, Wald $=0.114$, $p=0.007)$. The findings from this preliminary study may be used by health professionals as a noninvasive method to predict the inflammation caused by osteoarthritis.
\end{abstract}

Keywords: Infrared Thermography, Inflammatory Response,Elderly, Arthritis
*Correspondence to Author:

Miarka, B.

Universidade Federal de Juiz de Fora - Campus Governador Valadares

How to cite this article:

Miarka, B., Quintana, M.S, Moreira, D.G, Brito, C.J. Infrared Thermography as a Predictor of Inflammatory Response in the Elderly with Arthritis.International Research Journal of Optics and Photonics, 2018, 1:5

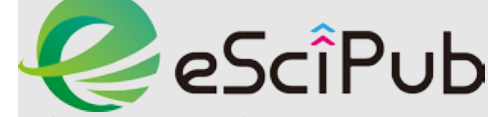
eSciPub LLC, Houston, TX USA. Website: http://escipub.com/ 